\title{
Gide ou l'identité en question, Jean-Michel WITTMANN
}

\section{Riccardo Benedettini}

\section{(2) OpenEdition \\ Journals}

\section{Edizione digitale}

URL: http://journals.openedition.org/studifrancesi/15775

DOI: 10.4000/studifrancesi. 15775

ISSN: 2427-5856

\section{Editore}

Rosenberg \& Sellier

\section{Edizione cartacea}

Data di pubblicazione: 1 décembre 2018

Paginazione: 526

ISSN: 0039-2944

\section{Notizia bibliografica digitale}

Riccardo Benedettini, «Gide ou l'identité en question, Jean-Michel witTmann», Studi Francesi [Online], 186 (LXII | III) | 2018, online dal 01 janvier 2019, consultato il 06 janvier 2021. URL: http://

journals.openedition.org/studifrancesi/15775 ; DOI: https://doi.org/10.4000/studifrancesi. 15775

Questo documento è stato generato automaticamente il 6 janvier 2021.

\section{(c) (†)}

Studi Francesi è distribuita con Licenza Creative Commons Attribuzione - Non commerciale - Non opere derivate 4.0 Internazionale. 


\title{
Gide ou l'identité en question, Jean- Michel WITTMANN
}

\author{
Riccardo Benedettini
}

\section{NOTIZIA}

Gide ou l'identité en question, sous la direction de Jean-Michel witTMAnN, Paris, Classiques Garnier, 2017, «Bibliothèque gidienne» 4, $342 \mathrm{pp}$.

1 Tema del convegno tenutosi a Metz nella primavera del 2015 era stato Gide, l'identité à l'épreuve de la littérature. Questo volume, a cura dell'organizzatore J.-M. Wittmann, ne pubblica ora diciannove contributi riuniti in quattro parti: "Éclatement et recomposition du moi» (pp.17-61), «De la construction du moi à l'élaboration d'une image d'auteur» (pp.63-147), «Les antinomies de l'individu et de la communauté. De l'individualisme à la question des minorités» (pp. 149-246) e «Les identités collectives en question. Gide et l'étranger, Gide à l'étranger» (pp.247-328). Sappiamo dall'«Introduction» (pp.7-16) che «l'œuvre d'André Gide apparaît comme un lieu privilégié pour observer cette mutation [quella dell'identità, o delle identità] dans l'écriture du sujet» (p. 8) e che l'uso di tale nozione di "identità" inizia, come insegna Cl. Lévi-Strauss nel 1977, con la sua stessa "critica". In tale contesto, nella propria opera Gide costruisce l'identità grazie a un costante dialogo, con sé e con gli altri: nel primo caso, ritoccando continuamente il proprio portrait; nel secondo, affrontando gli altri nelle maniere più diverse.

2 Per offrire la giusta prospettiva sul problema, le prime due parti del volume analizzano questa nozione identitaria come inseparabile dal moi gidiano. Su ciò si soffermano $\mathrm{i}$ seguenti contributi: D.H. WALKER, La goutte, la vague et la mer. Substance et formes du moi gidien, pp. 19-35; A. YOSHII, Le début et la fin de "Si le grain ne meurt". Une analyse textuelle, pp. 37-45; A. GOULET, Le protéisme de Gide à l'épreuve des "Caves du Vatican”, pp. 47-61; P. POLLARD, Gide traducteur à la recherche de son alter ego. "Arden of Faversham" et "The Autobiography of Mark Rutherford”, pp. 65-75; F. TOUDOIRE-SURLAPIERRE, «Il y a un Gide intime 
qu'on ne connaît pas. Coupez», pp. 77-99; P. SCHNYDER, L'identité gidienne au prisme de la lettre, pp.101-116; S. BERTRAND, "Un livre est toujours une collaboration». L'aphorisme paratextuel, une co-construction de l'«image d'auteur»?, pp. 117-128; M. KOFFEMAN, "Une voix dans un chœur risque de n'être point entendue». André Gide et la "Nouvelle Revue Française", 1908-1914, pp. 129-147. Le altre due parti, dedicate al rapporto tra l'individuo e il gruppo, sono segnate dall'immagine di Gide difensore dell'individualismo di fronte a un'identità collettiva, dove ciò che più sembra interessare lo scrittore, protestante e omosessuale, sono le minoranze: ricordiamo la problematica dell'identità omosessuale, di rilievo per l'analisi della trilogia detta femminista e in particolare del romanzo Geneviève, un'opera risultato di una "inquietudine" che torna nella riflessione su un singolare «Gide le Juif» (p. 243), dove ci si sofferma sull'antisemitismo dell'epoca, oltre che sull'emancipazione femminile (Geneviève, appunto) e sulle opinioni riguardanti scrittori quali Céline o Jouhandeau. I contributi sono i seguenti: F. BOMPAIRE, «Je» et «les autres». Ironie et sociologie dans "Les Caves du Vatican" d'André Gide, pp. 151-165; R. MORII, L'individu face au groupe. Gide et le solidarisme, pp. 167-184; J.-M. WITTMANN, De l'individualisme au féminisme. La question de la minorité dans la trilogie de "L'École des femmes", pp. 185-196; E. GUERINI, André Gide et Julien Green. Pour une prise de parole de l'homosexualité en littérature, pp.197-210; F. LESTRINGANT, André Gide, la littérature et les Juifs, pp. 211-246; H. BATYDELALANDE, "Une route qui s'écarte de plus en plus». Gide et la crise de l'identité nationale (1939-1945), pp. 249-263; C. LATROUITTE-ARMSTRONG, Terre normande, nourriture de l'ailleurs. Orphelins gidiens en quête de soi, pp. 265-273; P. MASSON, Identité du colonisé, pp. 275-286; M. zORICA, L'identité russe et soviétique à l'épreuve du regard gidien, pp. 287-302; C. SAGGIOMO, De Gide à Leonardo Sciascia. Un avatar italien de Nathanaël, pp. 303-314; M. KARELSON, André Gide et Johannes Semper, deux «contemporains capitaux», pp. 315-328. Il volume si chiude con l'«Index des noms» (pp. 329-332), che ben rende la vastità dell'investigazione. 